\title{
Turnstyle gridlock: Passenger (corpuscular) overload or slow-moving train?
}

\author{
Nancy S. Ghanayem, MD, ${ }^{a}$ and Ronald K. Woods, $\mathrm{MD}, \mathrm{PhD}^{\mathrm{b}}$
}

\footnotetext{
From the Divisions of ${ }^{\mathrm{a}}$ Pediatric Critical Care and ${ }^{\mathrm{b}}$ Cardiothoracic Surgery, Medical College of Wisconsin, Milwaukee, Wis.

Disclosures: Authors have nothing to disclose with regard to commercial support.

Received for publication Nov 9, 2016; accepted for publication Nov 10, 2016; available ahead of print Jan 5, 2017. Address for reprints: Nancy S. Ghanayem, MD, $9000 \mathrm{~W}$ Wisconsin Ave, Milwaukee, WI 53122 (E-mail: nghanaye@mcw.edu).

J Thorac Cardiovasc Surg 2017;153:956

$0022-5223 / \$ 36.00$

Copyright (C) 2016 by The American Association for Thoracic Surgery

http://dx.doi.org/10.1016/j.jtcvs.2016.11.021
}

The report in this issue of the Journal by Anderson and colleagues ${ }^{1}$ on initial postoperative hematocrit and early shunt thrombosis deserves a careful analysis. We find intuitively appealing the notion that a high hematocrit may increase the risk of early shunt thrombosis, and we congratulate Anderson and colleagues ${ }^{1}$ for introducing this notion. They base their "preliminary" findings on a cohort of 80 patients in which 5 of 12 shunt thromboses occurred early (between 2 and 4.5 hours after admission to the intensive care unit). After applying sophisticated statistical methodology, they concluded that for every additional 5 percentage points in hematocrit, the risk of shunt thrombosis more than doubled, an effect reduced by $41 \%$ when controlling for surgical era.

Although we appreciate the introduction of this notion and the preliminary data, we remain somewhat hesitant regarding wholesale acceptance of the validity of the conclusions for several reasons. Although not prohibitively so, 5 is a low number of events. Our lack of formal statistical expertise does not preclude a commonsense appreciation of the impact this small number may have on even the most sophisticated statistical methods. The actual hematocrits of the 5 patients were not listed, but from the graph we can approximate them as $37 \%, 48 \%, 49 \%, 51 \%$, and $56 \%$, with 3 of the events occurring within 3 hours of admission to the intensive care unit. Anderson and colleagues $^{1}$ justifiably excluded 1 patient with an initial hematocrit of $66 \%$ because exchange transfusion was initiated "rapidly." What was this patient's hematocrit after 2 to 3 hours, and did an event occur? If the resultant hematocrit was $50 \%$ and no thrombosis occurred, what magnitude of impact would this have had on results? According to the manufacturer of the Sysmex XN-9000 (Sysmex America, Inc, Lincolnshire, Ill), the precision of the measurements is $1.5 \%$. Anderson and colleagues ${ }^{1}$ do not describe whether this was factored in to the analysis. We suspect that the impact would be minimal, but we can't know.

The analysis accounted for approximately 20 potentially confounding variables. The postoperative blood transfusion variable was defined as the median value in the first 24 hours

\section{Reference}

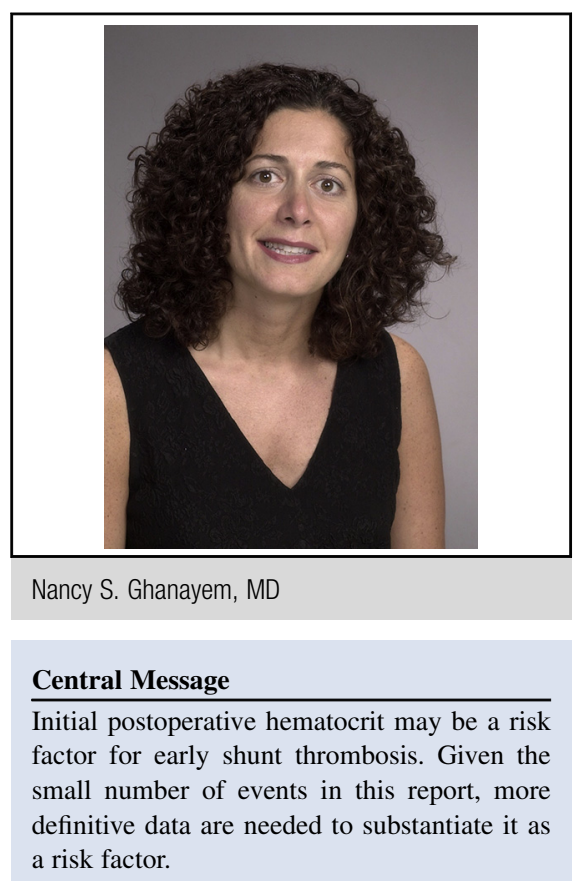

See Article page 947.

or until shunt occlusion. This would seem to introduce bias between the event and nonevent groups, with potentially lower values reported for the event group. In addition, as appropriately acknowledged by Anderson and colleagues, ${ }^{1}$ the lack of hemodynamic data (or indirect measures of cardiac output, such as regional oximetry or invasive mixed venous saturation) is a limitation of this work. We would emphasize that it is a significant limitation. A patient arriving in the intensive care unit with low cardiac output, particularly a patient with cyanosis or single ventricle, is not only considered at higher risk for thrombotic complications but may also be treated empirically with red blood cell transfusion, which in this case would potentially be masked by the method of comparing transfused volumes. Although the inotrope score may be useful, it is not a surrogate for the actual cardiac output state of the patient. Accordingly, is early shunt occlusion due predominantly to passenger (corpuscular) overload or to a slow-moving train?

1. Anderson BR, Blancha VL, Duchon JM, Chai P, Kalfa D, Bacha EA, et al. The effects of postoperative hematocrit on shunt occlusion for neonates undergoing single ventricle palliation. J Thorac Cardiovasc Surg. 2017;153:947-55. 